\title{
Women's iodine status and its determinants in an iodine-deficient area in the Kayes region, Mali
}

\author{
Liv E Torheim ${ }^{1, *}$, Gry I Granli ${ }^{2}$, Cheick S Sidibé ${ }^{3}$, Abdel K Traoré ${ }^{4}$ and Arne Oshaug ${ }^{1}$ \\ ${ }^{1}$ Akershus University College, PO Box 423, N-2001 Lillestrøm, Norway: ${ }^{2}$ Pedriatric Ward, Rikshospitalet, Oslo, \\ Norway: ${ }^{3}$ Ecole Secondaire de la Santé, Bamako, Mali: ${ }^{4}$ Faculté de Medicin, Farmacie et d'Odonto-Stomotoligie, \\ Université du Mali, Bamako, Mali
}

Submitted 17 June 2004: Accepted 25 October 2004

\begin{abstract}
Objective: To assess iodine status and its determinants in women of childbearing age in a rural area in the Kayes region, Mali, West Africa.

Design: Cross-sectional study where women's iodine status was indicated by urinary iodine concentration (UIC) and level of goitre based on palpation. Salt iodine was assessed semi-quantitatively at household level. Individual characteristics were collected using questionnaires.

Setting: Fifteen villages in a rural area in the Kayes region of Mali.

Subjects: Women aged $15-45$ years $(n=423)$.

Results: Median UIC was $2.7 \mu \mathrm{g} \mathrm{dl}^{-1}$, and only $6 \%$ of the women had adequate iodine status of UIC $>10 \mu \mathrm{g} \mathrm{dl}^{-1}$. Most women (60\%) had visible goitre, and only $9 \%$ were classified as without goitre. Only 39\% of the households were using salt with any iodine, and level of knowledge about salt iodisation was low. Main determinants of UIC were breast-feeding and level of salt iodisation; currently breast-feeding women had lower UIC, and UIC increased with increasing level of iodine in household salt. Prevalence of goitre was lower in older women with higher body mass index.

Conclusion: The study indicates severe iodine deficiency in the study area. Urgent action is needed to improve the situation through enforcing salt iodisation legislation and increasing the level of knowledge about the importance of iodised salt in the population.
\end{abstract}

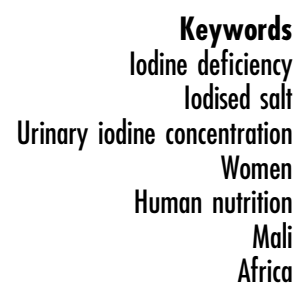

Iodine deficiency still constitutes the single greatest cause of preventable brain damage and mental retardation ${ }^{1}$. Iodine deficiency disorders (IDD) in utero is recognised as a cause of poor mental and cognitive development ${ }^{2}$. All degrees of iodine deficiency affect the thyroid function of the mother and neonate, and the mental development of the child ${ }^{1}$. The resulting mental deficiency has an immediate effect on child learning capacity, women's health, the quality of life of communities and economic production $^{3}$. Other consequences of iodine deficiency and subsequent inadequate thyroid hormone production include goitre, hypothyroidism, cretinism, congenital anomalies, increased perinatal mortality, stillbirths and abortions ${ }^{4}$. Much has been achieved in improving the coverage of households with iodised salt, which is the main intervention to address IDD. In developing countries approximately $66 \%$ of households are now using iodised salt $^{5}$. Recent estimates by the World Health Organization (WHO) indicate that 54 countries are still affected by iodine deficiency and nearly 2 billion individuals worldwide are iodine-deficient ${ }^{6}$.
In Mali, salt iodisation was adopted as the preventive method for iodine deficiency in 1995, and the same year legislation on salt iodisation was passed ${ }^{7}$. Most of the salt is imported from Senegal, and all imported salt should be fortified with at least $25 \mathrm{~g}$ iodine per $\mathrm{kg} \mathrm{salt}{ }^{8}$. No nationwide survey of the IDD situation in Mali has been conducted. A Demographic Health Survey (DHS) in 2001 found that $74 \%$ of households were using iodised salt ${ }^{9}$. An assessment of the food and nutrition situation in Bafoulabé in the Kayes region was conducted in 1997 as part of a collaboration between researchers and a local nongovernment organisation. The survey registered cases of visible goitre only, and found a high prevalence in the area $^{10}$. The present study was conducted to investigate further the iodine situation in the area, both the extent of iodine deficiency and determinants for planning suitable actions. Women were targeted since they constitute a group that is particularly vulnerable to $\mathrm{IDD}^{3}$.

The main objective of the present paper is to assess iodine status and its determinants in women of childbearing age in this rural area in the Kayes region of Mali. 


\section{Subjects and methods}

\section{Study area}

The study was done in Oussoubidiania development sector, Bafoulabé district, in the Kayes region of Western Mali. Oussoubidiania is a remote area of approximately 7500 inhabitants, where subsistence agriculture and raising livestock are the main livelihood activities ${ }^{11}$. The main ethnic group in this community is Kassonké. The most important foods are sorghum, maize, groundnuts and green leaves, and food insecurity is a seasonal concern $^{11}$

\section{Sample population}

The target population was women of reproductive age (15-45 years) recruited from all 15 villages that constituted Oussoubidiania development sector. A sample size of 300 women was needed, derived from an assumed prevalence of iodine deficiency of $50 \%$ and a $95 \%$ confidence interval $^{12}$. This corresponded to an estimated 160 households (including an estimated drop-out of 20\%). The number of households to be selected in each of the 15 villages was determined based on the size of village. The households were randomly selected in each village, and all women aged 15-45 years in the selected households were included. The final number of study participants was 423 women recruited from 150 different households. Women's response rate was $92 \%$, and the main reason for not participating was absence at the day of visit.

Characteristics of the study participants are shown in Table 1 . Median age was 25 years and age was skewed to the lower range of $15-45$ years. Most women (77\%) had given birth at least once, and median parity was 3 .

Table 1 Background characteristics of the study participants. Women aged $15-45$ years $(n=423$; Mali, 1999)

\begin{tabular}{lc}
\hline Characteristic & Value \\
\hline Age (years) & $25(18,33)^{\star}$ \\
Childbirths (number) $\dagger$ & $3(1,6)^{\star}$ \\
None & $97(23) \ddagger$ \\
$1-2$ & $101(24) \ddagger$ \\
$3-4$ & $86(20) \ddagger$ \\
$\geq 5$ & $138(33) \ddagger$ \\
Stillbirths (number) & \\
0 & $309(73) \ddagger$ \\
1 & $82(19) \ddagger$ \\
$>1$ & $32(8) \ddagger$ \\
Currently pregnant & $56(13) \ddagger$ \\
Currently breast-feeding & $156(37) \ddagger$ \\
Height (m) & $1.63(1.60,1.67)^{\star}$ \\
Weight $(\mathrm{kg})$ & $54.9(50.7,60.5)^{\star}$ \\
Body mass index $\left(\mathrm{kg} \mathrm{m}^{-2}\right) \S$ & $20.4(19.1,22.1)^{*}$ \\
$<18.5$ & $53(15) \ddagger$ \\
18.5 to $\leq 25$ & $291(80) \ddagger$ \\
$>25$ & $21(6) \ddagger$ \\
\hline
\end{tabular}

* Median (25th, 75th percentile).

† Includes live births and stillbirths.

$\ddagger n(\%)$.

$\S n=365$, since body mass index was calculated only for non-pregnant women, and height measures were missing for two of these.
Twenty-seven per cent of the women said they had experienced at least one stillbirth. Thirteen per cent of the women were currently pregnant, whereas 37\% were breast-feeding. No woman said she was both pregnant and breast-feeding. Body mass index (BMI) was in the lower range (median of $20.4 \mathrm{~kg} \mathrm{~m}^{-2}$ ), and $15 \%$ of the study participants were underweight $\left(\mathrm{BMI}<18.5 \mathrm{~kg} \mathrm{~m}^{-2}\right)$.

\section{Data collection}

Five fieldworkers were recruited locally. All were fluent in both the local language (Kassonké) and French, and had at least 3 years' higher education in health or social work. Two fieldworkers had experience from previous surveys. The fieldworkers underwent a week of theoretical and practical training prior to the data collection, and they participated in a pilot test of the methods and the subsequent modifications. During the study, two supervisors (G.I.G. and C.S.S.) checked all data collected daily for errors and completeness.

A pre-coded questionnaire was administered to the women by interview in the local language. It included questions on number of childbirths and number of stillbirths, and whether she was currently pregnant and/or breast-feeding. The women were weighed lightly clothed, using digital scales (Soehnle 7505, $100 \mathrm{~g}$ precision). Standing height was measured using a locally made stadiometer with $0.1 \mathrm{~cm}$ precision. The size of each woman's thyroid gland was visually inspected and palpated, and was graded according to the 1960 WHO criteria $^{13}$ with five categories of goitre severity. A sample of morning urine was obtained from each participant. The urine samples were kept frozen until analysed. Urinary iodine concentration (UIC) was measured using the Sandell-Kolthoff reaction ${ }^{14,15}$.

The household head, the traditional provider of salt, was asked whether the household salt was iodised, as well as its provenance. The household salt was tested for iodine content using a semi-quantitative test kit (Machine Build Industries, India). These are field test kits for testing salt fortified with potassium iodate $\left(\mathrm{KIO}_{3}\right)$. Potassium iodate is the compound used for fortification of the salt imported from Senegal to Mali. The iodine concentration in the salt was determined visually from a colour chart with five codes: 0, 25, 50, 75 and above 100 parts of iodine per million (ppm).

Study permission was obtained from the Malian National Centre for Scientific and Technological Research, district authorities and village leaders. Each woman gave informed, oral consent to participate. The survey was conducted in November-December 1999.

\section{Data analysis}

The five groups of goitre of the 1960 classification were collapsed into three groups that corresponded to the simplified classification suggested by WHO, the United Nations Children's Fund (UNICEF) and the International 
Council for Control of Iodine Deficiency Disorders (ICCIDD) in $1994^{3,12}$ : grade 0 remained the same (not palpable), grade $1 \mathrm{~A}$ and $1 \mathrm{~B}$ equalled the new grade 1 (palpable but not visible), whereas grade 2 to 3 became the new grade 2 (visible goitre when the neck is in normal position). The re-classification was done to ensure large enough groups in the data analysis.

The IDD indicators assessed (UIC, goitre and iodine content of household salt) were compared with WHO/ICCIDD/UNICEF epidemiological criteria for assessing the severity of IDD in a population ${ }^{3}$. According to these guidelines, median UIC below $2.0 \mu \mathrm{g} \mathrm{dl}^{-1}$ indicates severe iodine deficiency, between 2.0 and $4.9 \mu \mathrm{g} \mathrm{dl}^{-1}$ indicates moderate iodine deficiency, and between 5.0 and $9.9 \mu \mathrm{g} \mathrm{dl}^{-1}$ shows mild iodine deficiency is present. Furthermore, a geographical area with a goitre rate above $30 \%$ is classified as severely iodine-deficient, between 20 and $29.9 \%$ as moderately iodine-deficient and between 5 and $19.9 \%$ as mildly iodine-deficient. One goal for sustainable elimination of IDD has been expressed as more than $90 \%$ of the households use adequately iodised salt, which has been defined as at least $15 \mathrm{ppm}$ in populations which consume on average $10 \mathrm{~g}$ salt per day ${ }^{3}$.

Continuous variables are expressed as median and percentiles, and were compared by Kruskal-Wallis and Mann-Whitney tests or Spearman's rank correlation. Categorical variables were compared using the chi-square test. Linear regression was used to identify the determinants of UIC, using the square root of UIC to obtain a normal distribution. $P$-values of less then 0.05 were considered significant.

\section{Results}

Median UIC of the study participants was $2.7 \mu \mathrm{g} \mathrm{dl}^{-1}$ (Table 2). Most women were severely or moderately iodine-deficient (35\% and 40\%, respectively). Adequate iodine status of $>10 \mu \mathrm{g}$ iodine/dl urine was found in only $6 \%$ of the sample. Table 2 also shows that only $9 \%$ of the women were classified as without goitre based on palpation, and most women (60\%) had visible goitre (grade 2).

The majority of the households (61\%) used salt with no iodine as tested with the semi-quantitative test kit (Table 3 ). Only $2 \%$ of the respondents said their household salt was iodised, and most households did not know whether their salt was iodised (69\%). There was no relationship between the household's perception of whether the salt was iodised and the tested level of iodine in the household salt (data not shown).

Table 4 shows the association between the various characteristics of the study participants and their UIC. There was a positive association between the women's UIC and iodine level in household salt $(P<0.001)$. Among those using salt without any detected iodine,
Table 2 lodine status of women ( $n=423$; Mali, 1999)

\begin{tabular}{lc}
\hline lodine status indicator & Value \\
\hline Urinary iodine $\left(\mu \mathrm{g} \mathrm{dl}^{-1}\right)^{\star}$ & $2.7(1.3,4.9) \dagger$ \\
$<2.0$ & $140(35) \ddagger$ \\
$2.0-4.9$ & $170(40) \ddagger$ \\
$5.0-9.9$ & $78(18) \ddagger$ \\
$\geq 10.0$ & $26(6) \ddagger$ \\
Goitre - 1991 classification§ & \\
Grade 0 & $37(9) \ddagger$ \\
Grade 1 & $131(31) \ddagger$ \\
Grade 2 & $255(60) \ddagger$ \\
Goitre - 1960 classification $\emptyset$ & $37(9) \ddagger$ \\
Grade 0 & $30(7) \ddagger$ \\
Grade 1A & $101(24) \ddagger$ \\
Grade 1B & $222(52) \ddagger$ \\
Grade 2 & $33(8) \ddagger$ \\
Grade 3 &
\end{tabular}

${ }^{*}$ To convert to $\mu \mathrm{mol} \mathrm{dl}{ }^{-1}$, multiply by 0.0079 .

† Median (25th, 75th percentile).

$\ddagger n(\%)$.

$\S$ Grade 0 - no palpable goitre; grade 1 - not visible but palpable goitre; grade 2 - visible goitre.

I Grade 0 - no palpable goitre; grade $1 \mathrm{~A}$ - not visible but palpable goitre with neck in normal position; grade $1 \mathrm{~B}$ - not visible but palpable goitre with neck in normal position, and visible with neck in extended position; grade 2 - visible and palpable goitre with neck in normal position, and goitre is not visible at a distance of more than $10 \mathrm{~m}$; grade 3 - visible goitre at a distance of $10 \mathrm{~m}$.

median UIC was $1.9 \mu \mathrm{g} \mathrm{dl}^{-1}$, below the WHO/ICCIDD/ UNICEF cut-off for severe iodine deficiency ${ }^{3}$. The women from households using salt with 25 and 50 ppm iodine fell in the category of moderately iodine-deficient, with median UIC of 3.4 and $4.0 \mu \mathrm{g} \mathrm{dl}^{-1}$, respectively. Even those using salt with at least $75 \mathrm{ppm}$ were mildly iodinedeficient, with median UIC of $7.0 \mu \mathrm{g} \mathrm{dl}^{-1}$. Among women from households using salt with any detected iodine (at least $25 \mathrm{ppm}$ ) only $13 \%$ had an adequate UIC above $10 \mathrm{gg} \mathrm{dl}^{-1}$ (data not shown).

The women who were currently breast-feeding had significantly lower UIC compared with both those neither pregnant nor breast-feeding and those who were pregnant (median values of $2.3,3.0$ and $2.8 \mu \mathrm{g} \mathrm{dl}^{-1}$, respectively, $P=0.008)$. There was no difference in UIC between pregnant and non-pregnant women. None of the other characteristics tested (parity, stillbirths, age and BMI) were found to have any association with UIC (Table 4).

To separate the effect of breast-feeding from the use of iodised salt, ordinary least-squares regression was used

Table 3 Household use of iodised salt ( $n=150$; Mali, 1999)

\begin{tabular}{lc}
\hline Variable & $n(\%)$ \\
\hline Salt iodisation level (ppm) & \\
0 & $92(61)$ \\
25 & $28(19)$ \\
50 & $19(13)$ \\
75 & $10(7)$ \\
100 & $1(0)$ \\
Answer to question on whether household salt was iodised & \\
Not iodised & $44(29)$ \\
lodised & $3(2)$ \\
Did not know & $103(69)$ \\
\hline
\end{tabular}


Table 4 Association between urinary iodine $\left(\mu \mathrm{g} \mathrm{dl}^{-1}\right)$ and background and nutritional characteristics $(n=423$; Mali, 1999)

\section{Median}

(25th, 75th percentile)

\begin{tabular}{|c|c|}
\hline \multirow{2}{*}{\multicolumn{2}{|c|}{ lodine level in salt (ppm) }} \\
\hline & \\
\hline $0(n=249)$ & $1.9(0.9,3.2)$ \\
\hline $25(n=70)$ & $3.4(2.7,5.6)$ \\
\hline $50(n=73)$ & $4.0(2.6,7.8)$ \\
\hline$\geq 75^{\star}(n=31)$ & $7.0(3.7,11.1)$ \\
\hline$P$-valuet & $<0.001$ \\
\hline \multicolumn{2}{|l|}{ Parity (number) } \\
\hline $0(n=97)$ & $3.0(1.9,5.3)$ \\
\hline $1-2(n=101)$ & $2.6(1.3,5.1)$ \\
\hline $3-4(n=86)$ & $2.7(0.9,4.9)$ \\
\hline$\geq 5(n=138)$ & $2.6(1.3,4.5)$ \\
\hline$P$-valuet & 0.2 \\
\hline \multicolumn{2}{|l|}{ Stillbirths (number) } \\
\hline $0(n=309)$ & $2.7(1.4,5.0)$ \\
\hline $1(n=82)$ & $2.9(1.5,5.2)$ \\
\hline$\geq 2(n=32)$ & $2.2(1.1,3.6)$ \\
\hline$P$-valuet & 0.1 \\
\hline \multicolumn{2}{|l|}{ Current reproductive status } \\
\hline $\begin{array}{l}\text { Neither pregnant nor } \\
\text { breast-feeding }(n=212)\end{array}$ & $3.0(1.6,5.2)$ \\
\hline Pregnant $(n=56)$ & $2.8(1.6,5.6)$ \\
\hline Breast-feeding $(n=156)$ & $2.3(1.0,3.8)$ \\
\hline$P$-valuet & 0.008 \\
\hline \multicolumn{2}{|l|}{ Age (years) } \\
\hline$r$ & -0.04 \\
\hline$P$-value & 0.4 \\
\hline \multicolumn{2}{|l|}{ Body mass index $\left(\mathrm{kg} \mathrm{m}^{-2}\right) \ddagger$} \\
\hline$r$ & 0.00 \\
\hline$P$-value & 1.0 \\
\hline
\end{tabular}

$r$ - Spearman's correlation coefficient.

${ }^{*}$ Women from households using salt with $75 \mathrm{ppm}(n=29)$ and with $100 \mathrm{ppm}(n=2)$ added.

†Differences tested with Kruskal-Wallis one-way analysis of variance. $\ddagger$ Includes only non-pregnant women.

(Table 5). Both variables had significant association with UIC when entered into the same model, which explained $24 \%$ of the variation. Figure 1 illustrates the impact of iodisation level of household salt and breast-feeding on UIC.

The same characteristics, as well as UIC, were analysed in relation to goitre (Table 6). There was a tendency towards a lower prevalence of visible goitre in the groups with higher UIC $(P=0.07)$. Age and BMI were found to be associated with goitre; goitre prevalence was highest among the youngest and thinnest groups of women. Figure 2 illustrates that the association between BMI and goitre existed only in the highest age group. Most of those without goitre were in the highest age group and had the highest BMI. The association between age and goitre was similar, and it existed only in the highest BMI tertile (data not shown).

Parity was also found to be associated with goitre. Nulliparous women had the highest prevalence of goitre, with $98 \%$ classified as goitrous grade 1 or 2 , whereas among those with at least five children, $84 \%$ were classified as having goitre $(P=0.003)$. However, this association did not remain significant when controlling for age. No relationships were found between goitre and iodine level in salt, current reproductive status or number of stillbirths.

\section{Discussion}

Our study showed widespread iodine deficiency among women in this area of rural Western Mali. Median UIC was $2.7 \mu \mathrm{g} \mathrm{dl}^{-1}$ and only $6 \%$ had adequate UIC, i.e. above $10 \mu \mathrm{g} \mathrm{dl}^{-1}$. As many as $75 \%$ of the women had UIC below $5 \mu \mathrm{g} \mathrm{dl}^{-1}$, being moderately to severely iodine-deficient according to the epidemiological criteria set by WHO/IC$\mathrm{CIDD} / \mathrm{UNICEF}^{3}$. The overall prevalence of goitre of $91 \%$ was extremely high. It greatly exceeded the limit of $10 \%$ where IDD is considered a public health problem ${ }^{3}$. Only $39 \%$ of the households used iodised salt (at least $25 \mathrm{ppm}$ ), and knowledge about iodised salt was low.

All three IDD indicators investigated show that Oussoubidiania is a pocket of extreme iodine deficiency where specific measures are needed. Recent studies from other parts of Mali give a less grim picture of the IDD situation in the country. A study was done in 1999 by ThyroMobil (a van equipped with ultrasound for measurement of thyroid volume, a computer and a deep freezer) and included samples of schoolchildren in nine sites around Segou in Mali ${ }^{16}$. The study found a median UIC of $20.3 \mu \mathrm{g} \mathrm{dl}^{-1}$ and $66 \%$ of the sample had UIC above $10 \mu \mathrm{g} \mathrm{dl}^{-1}$. Total goitre rate was $13 \%$, as assessed by ultrasonography. A study of adolescent girls (10-15 years of age) in the region of Segou ${ }^{17}$ found a mean UIC of $9.3 \mu \mathrm{g} \mathrm{dl}^{-1}$ and $33 \%$ had UIC above $10 \mu \mathrm{g} \mathrm{dl}^{-1}$. In the DHS of $2001^{9}$, overall $74 \%$ of households in Mali were found to be using iodised salt, and in the region of Kayes the prevalence was 69\%. There is no evidence pointing

Table 5 Determinants of urinary iodine ${ }^{*}(n=423$; Mali, 1999)

\begin{tabular}{lcrrr}
\hline Variable & $\begin{array}{c}\text { Unadjusted effect } \\
\text { (95\% confidence interval) }\end{array}$ & $P$-value & $\begin{array}{c}\text { Adjusted effect† } \\
\text { (95\% confidence interval) }\end{array}$ & $P$-value \\
\hline Constant & & & $1.25(1.10,1.40)$ & $<0.001$ \\
lodine level in saltł & $0.45(0.38,0.55)$ & $<0.001$ & $0.47(0.39,0.55)$ & $<0.001$ \\
Currently breast-feeding§ & $0.21(0.02,0.40)$ & 0.032 & $0.23(0.07,0.40)$ & 0.006 \\
$R^{2}$ & & & 0.24 &
\end{tabular}

* Square root of urinary iodine concentration $\left(\mu \mathrm{g} \mathrm{dl}^{-1}\right)$.

† Adjusted for the other variable in the table in multiple regression analysis.

¥Categories of iodine level in salt: $0=0 \mathrm{ppm} ; 1=25 \mathrm{ppm} ; 2=50 \mathrm{ppm} ; 3=\geq 75 \mathrm{ppm}$.

$\S$ Breastfeeding dummy: $0=$ yes; $1=$ no. 
Women's iodine status in Kayes region, Mali

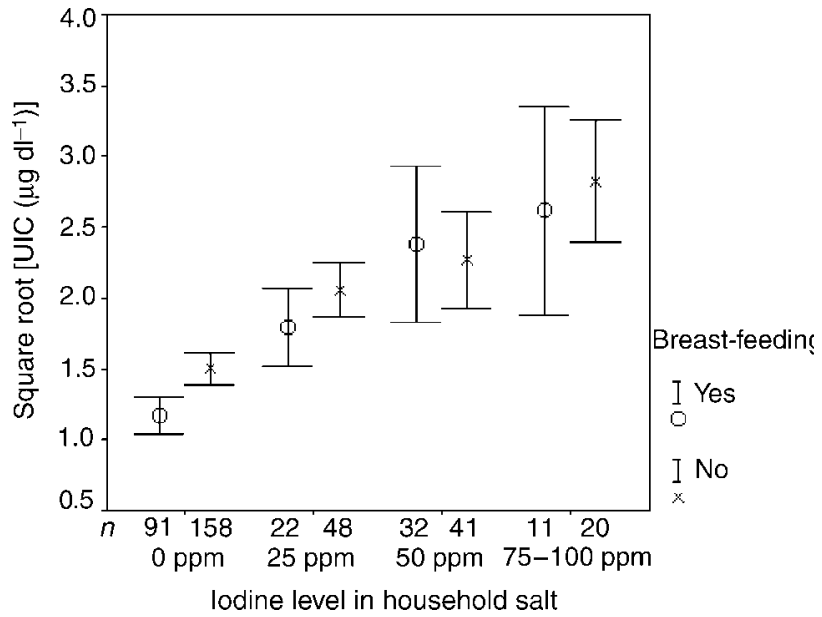

Fig. 1 Comparison of (square-root) urinary iodine concentration (UIC) in breast-feeding and non-breast-feeding women according to level of household salt iodisation as measured by rapid test kit $(n=423$; Mali, 1999)

towards the Kayes region as being a particularly severely affected region in Mali. Much of the focus on iodine deficiency has been in the central regions, like Segou and Mopti.

Oussoubidiania is a remote and relatively inaccessible area of the Kayes region, which might contribute to the severe IDD situation. It is unclear whether the salt

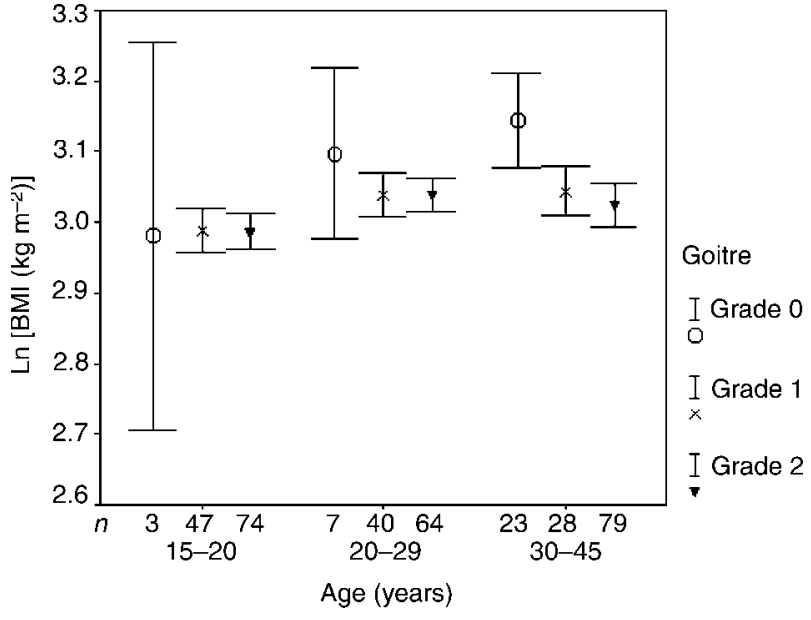

Fig. 2 Comparison of (In-transformed) body mass index (BMI) between women with no goitre (grade 0), palpable goitre (grade $1)$ and visible goitre (grade 2$)$ in three age groups $(n=423$; Mali, 1999)

reaching the area was not iodised at all, or whether there had been a loss of iodine due to storage over longer periods. High losses of iodine have been shown from salt packed in high-density polyethylene bags ${ }^{18}$. This was the packaging material mainly used at storage and retail level in the study area. In their study from the plains of Nepal, Schulze et al. ${ }^{19}$ showed that urinary iodine of pregnant

Table 6 Association between goitre prevalence (\%) and background and nutritional characteristics $(n=423 ;$ Mali, 1999)

\begin{tabular}{|c|c|c|c|c|}
\hline & Grade $0(n=31)$ & Grade $1(n=131)$ & Grade $2(n=255)$ & $P$-value* \\
\hline \multicolumn{5}{|l|}{ lodine level in salt (ppm) } \\
\hline $0(n=249)$ & 10 & 29 & 61 & \multirow[t]{2}{*}{0.5} \\
\hline$>0(n=174)$ & 7 & 34 & 59 & \\
\hline \multicolumn{5}{|l|}{ Urinary iodine concentration $\left(\mu \mathrm{g} \mathrm{dl}^{-1}\right)$} \\
\hline$<2(n=149)$ & 7 & 31 & 62 & \multirow[t]{4}{*}{0.07} \\
\hline $2-4.9(n=170)$ & 10 & 25 & 65 & \\
\hline $5-9.9(n=78)$ & 8 & 37 & 55 & \\
\hline$\geq 10(n=26)$ & 8 & 54 & 38 & \\
\hline \multicolumn{5}{|l|}{ Parity (number) } \\
\hline $0(n=97)$ & 2 & 36 & 62 & \multirow[t]{4}{*}{0.003} \\
\hline $1-2(n=101)$ & 9 & 34 & 57 & \\
\hline $3-5(n=86)$ & 5 & 36 & 59 & \\
\hline$\geq 5(n=138)$ & 16 & 22 & 62 & \\
\hline \multicolumn{5}{|l|}{ Stillbirths (number) } \\
\hline $0(n=309)$ & 7 & 32 & 61 & \multirow[t]{3}{*}{0.3} \\
\hline $1(n=82)$ & 12 & 29 & 59 & \\
\hline$\geq 2(n=32)$ & 16 & 22 & 62 & \\
\hline \multicolumn{5}{|l|}{ Current reproductive status } \\
\hline Not pregnant or breast-feeding $(n=212)$ & 9 & 30 & 61 & \multirow[t]{3}{*}{0.9} \\
\hline Pregnant $(n=55)$ & 7 & 29 & 64 & \\
\hline Breast-feeding $(n=156)$ & 8 & 33 & 58 & \\
\hline \multicolumn{5}{|l|}{ Age (years, tertiles) } \\
\hline $15-20(n=142)$ & 2 & 34 & 63 & \multirow[t]{3}{*}{$<0.001$} \\
\hline $21-29(n=131)$ & 6 & 36 & 58 & \\
\hline $30-45(n=150)$ & 17 & 23 & 59 & \\
\hline \multicolumn{5}{|l|}{ Body mass index $\left(\mathrm{kg} \mathrm{m}^{-2}\right.$, tertiles) $\dagger$} \\
\hline $14.0-19.6(n=121)$ & 7 & 26 & 67 & \multirow[t]{3}{*}{$<0.001$} \\
\hline $19.7-21.4(n=122)$ & 2 & 43 & 55 & \\
\hline $21.5-35.4(n=122)$ & 19 & 25 & 57 & \\
\hline
\end{tabular}

Grade 0 - no palpable goitre; grade 1 - not visible but palpable goitre; grade 2 - visible goitre.

${ }^{*}$ Differences tested with chi-squared test.

†Includes only non-pregnant women. 
and lactating women and salt iodine covaried markedly by season, and were highest during hot and dry pre-monsoon months and lowest during and following the humid monsoon season. Our study was conducted in a cooler period some months after the rainy season, with a climate that should not have had adverse effects on the iodine content of the salt. Iodine may nevertheless have been lost from salt during transportation or storage.

Spot checks by the study team of salt at storage and retail level found both non-iodised salt and salt with low iodine (ppm) content in bags marked as being iodised. There were also bags not marked as being iodised, containing non-iodised salt. Current Malian legislation prohibits import and distribution of non-iodised salt. Although the study was done in 1999, no concrete action has been taken at national level to improve the situation. These results therefore point to a need for urgent control and monitoring of iodine content in salt at production, import and resale points. This should be based on enforcement of the existing legislation. An in-depth study of the origin of salt used in this area, mapping of salt importers and training of these are necessary to plan and implement an effective monitoring system. Efforts to ensure adequate iodine levels in salt at all points should be combined with campaigns to increase population awareness about the importance of iodine and create public demand for iodised salt.

\section{Determinants of UIC}

The main determinant of UIC was the level of iodine in the household salt. However, despite the positive correlation between UIC and content of iodine in household salt, most of the women using salt with iodine level of $25 \mathrm{ppm}$ or above still had UIC below $10 \mu \mathrm{g} \mathrm{dl}^{-1}$ (77\%). These results indicate that the recommended iodine content of $15 \mathrm{ppm}$ at household level may not be sufficient for sustaining an adequate iodine status in women of fertile age in this area. Dietary surveys conducted in the area have indicated a daily salt intake of around $10 \mathrm{mg}^{20,21}$, which is the basis for the current level of iodine fortification. Possible explanations for the lower than expected UIC in women from households using iodised salt could be consumption of food made with salt other than that tested in the household or loss of iodine during cooking. Studies have shown losses of up to $70 \%$ of salt iodine during cooking ${ }^{22}$. Imprecise or inaccurate measurement of iodine level in the household salt must also be considered. An evaluation of rapid test kits showed that they might lead to overestimation of the iodine content in salt ${ }^{23}$. Nevertheless, our results demonstrate the necessity of assessing UIC, and not only salt iodine content, in monitoring IDD.

Pregnancy was not found to be associated with UIC, unlike what was found in a study from another iodinedeficient area in Sudan ${ }^{24}$. Increased thyroid hormone requirements ${ }^{25}$ and increased iodine needs for the developing foetus are combined with an increased renal clearing of iodine during pregnancy ${ }^{26}$. It is therefore not evident that pregnancy will result in reduced UIC. Brander et $a l .{ }^{27}$ reported, in a study from Switzerland, significantly higher UIC in pregnant women in their first trimester compared with controls who were mildly iodine-deficient. Schulze et $a l .{ }^{19}$ found higher UIC in women during pregnancy compared with the same subjects during lactation in a moderately iodine-deficient area in Nepal.

Breast-feeding women had lower UIC than non-breastfeeding women, but only among those using salt with no iodine or low levels of iodine ( $0-25 \mathrm{ppm})$. Reduced iodine status during breast-feeding has been found also in other studies $^{19,24}$, and is probably partly a reflection of the iodine excretion in breast milk. The iodine concentration of human milk varies widely linked to maternal iodine intake $^{28}$. Undoubtedly, the low iodine status of the pregnant and breast-feeding women in this study may lead to a negative impact on the mental development of the foetus and the neonate ${ }^{1}$.

\section{Determinants of goitre}

Goitre prevalence decreased with age and parity. Regarding the toll repeated pregnancies and breastfeeding periods take on women's iodine status, this was surprising. These results were contradictory to other studies that have shown an increasing thyroid enlargement with age in women in areas of severe ${ }^{29}$ or moderate to mild iodine deficiency ${ }^{30,31}$. Parity has also been related to increased thyroid volume in moderately iodinedeficient areas ${ }^{30,32}$. It has been suggested that there is no effect of age per se, but that the relationship between thyroid size and age is solely due to parity ${ }^{30}$. The higher levels of goitre found in the nulliparous, as compared with the multiparous, in our study might reflect the young age of the first group ( $81 \%$ were less than 20 years old). These young women might have had an increased need for iodine due to increased production of thyroid hormones during puberty.

Goitre status was not related to either current pregnancy or breast-feeding in our study. This was unexpected, since pregnancy has been reported to bring about goitre even in moderately iodine-deficient areas of Europe $\mathrm{e}^{33,34}$. Goitres formed during gestation may regress only partially after parturition $^{35}$. It has therefore been suggested that pregnancy represents an environmental factor that may help explain the higher prevalence of goitre and thyroid disorders in women compared with men ${ }^{36}$.

There was a negative association between goitre prevalence and BMI. Some studies have indicated that malnutrition might in itself lead to abnormal thyroid function $^{37}$. In our study, the negative relationship between BMI and goitre was found only among the oldest women. One explanation for this observation could be that a high BMI in older women reflected that they had not given birth for some time. This could have allowed iodine and energy stores depleted owing to the strains of pregnancy and 
breast-feeding to be restored. This study did not give any information about when the women had last given birth; however, fertility decreased with age.

Misclassification is a major problem of assessment of thyroid enlargement by palpation ${ }^{38}$ and cannot be ruled out as an explanation for our results. A systematic misclassification would give a type 1 error (establish a non-existing association), whereas random misclassification would give a type 2 error (failing to observe an existing association) ${ }^{39}$. It is possible that younger and thinner women have wrongly been classified as goitrous to a larger extent than older women with higher BMI.

\section{Conclusion}

In conclusion, this study has shown a situation of severe iodine deficiency among women of childbearing age in this area of rural Kayes, Western Mali. Inadequate salt iodisation combined with increased need for iodine during pregnancy and lactation were the main determinants. Urgent action is needed to improve the situation through increased access to and knowledge about iodised salt.

\section{Acknowledgements}

Our thanks go to the women who patiently answered our questions and inquiries. Thanks also to the fieldworkers who did a painstaking job with great efforts. We greatly appreciate the support of the Stromme Foundation in Bamako and of AIDEB in Bafoulabé. This study was funded by the Stromme Foundation. We also thank UNICEF Mali for providing the semi-quantitative test kits to test for iodine in salt.

\section{References}

1 Delange F. The role of iodine in brain development. Proceedings of the Nutrition Society 2000; 59: 75-9.

2 Pharoah POD, Connolly KJ. Iodine deficiency in Papua New Guinea. In: Stanbury JB, ed. The Damaged Brain of Iodine Deficiency. New York: Cognizant Communication Corporation, 1994; 299-305.

3 World Health Organization (WHO)/International Council for Control of Iodine Deficiency Disorders/United Nations Children's Fund. Assessment of Iodine Deficiency Disorders and Monitoring Their Elimination - A Guide for Programme Managers. Geneva: WHO, 2001.

4 Hetzel BS, Dunn JT, Stanbury JB. The Prevention and Control of Iodine Deficiency Disorders. Amsterdam: Elsevier, 1987.

5 United Nations Children's Fund (UNICEF). The State of the World's Children 2004. New York: UNICEF, 2003.

6 United Nations Standing Committee on Nutrition (SCN). 5th Report on the World Nutrition Situation. Geneva: SCN, 2004.

7 World Health Organization (WHO)/United Nations Children's Fund/International Council for Control of Iodine Deficiency Disorders. Conference on Sustainable Elimination of Iodine Deficiency Disorders in Africa by the Year 2000. Geneva: WHO, 1998.

8 Global Micronutrient Project. Iodine Situation in Mali [online]. New Orleans, LA: University of Tulane. Available at http://www.tulane.edu/ internut/Countries/Mali/ malixx.html. Accessed April 2004.

9 Cellule de Planification et de Statistique du Ministère de la Santé (CPS/MS), Direction Nationale de la Statistique et de l'Informatique (DNSI) and ORC Macro. Enquête Démographique et de Santé au Mali 2001. Calverton, MD: CPS/MS, DNSI and ORC Macro, 2001.

10 Torheim LE. Assessing Dietary Intake in Rural Mali Challenges when People eat from Shared Plates. Oslo: Faculty of Medicine, University of Oslo, 2003.

11 Torheim LE, Ouattara F, Diarra MM, Thiam FD, Barikmo I, Hatløy A, et al. Nutrient adequacy and dietary diversity in rural Mali: association and determinants. European Journal of Clinical Nutrition 2004; 58: 594-604.

12 World Health Organization (WHO)/United Nations Children's Fund/International Council for Control of Iodine Deficiency Disorders. Indicators for Assessing Iodine Deficiency Disorders and Their Control through Salt Iodization. Geneva: WHO, 1994.

13 Perez C, Schrimshaw NS, Munoz JA. Technique of endemic goitre surveys. In: Endemic Goiter. World Health Organization (WHO) Monograph Series No. 44. Geneva: WHO, 1960; 369-83.

14 Dunn JT, Crutchfield HE, Gutekunst R, Dunn AD. Methods for Measuring Iodine in Urine. The Netherlands: International Council for Control of Iodine Deficiency Disorders, 1993.

15 Dunn JT, Crutchfield HE, Gutekunst R, Dunn AD. Two simple methods for measuring iodine in urine. Thyroid 1993 ; 3: $119-23$.

16 Kibambe N, Ouedraogo A, Acakpo A, Salami M. Projet Thyromobil en Afrique de L'Ouest (première phase). Rapport Final. Lome: Conseil International de Lutte contre les Troubles Dus à la Carence en Iode/Organisation Mondiale de la Santé/Centre Régional de Recherche en Alimentation et Nutrition/Fonds des Nations Unies pour l'Enfance, 2000.

17 Pawloski LR, Shier NW, Fernandez XE, Jamison PL. Examination of urinary iodine status from a sample of Malian adolescent girls. African Journal of Food, Agriculture, Nutrition and Development 2003; 3: 20-8.

18 Diosady LL, Alberti JO, Venkatesh Mannar MG, FitzGerald S. Stability of iodine in iodised salt used for correction of iodine-deficiency disorders II. Food and Nutrition Bulletin 1998; 19: 240-9.

19 Schulze KJ, West KP Jr, Gautschi LA, Dreyfuss ML, LeClerq SC, Dahal BR, et al. Seasonality in urinary and household salt iodine content among pregnant and lactating women of the plains of Nepal. European Journal of Clinical Nutrition 2003; 57: 969-76.

20 Torheim LE, Barikmo I, Hatløy A, Diakité M, Solvoll K, Diarra MM, et al. Validation of a quantitative food-frequency questionnaire for use in Western Mali. Public Health Nutrition 2001; 4: 1267-77.

21 Parr CL, Barikmo I, Torheim LE, Ouattara F, Kaloga A, Oshaug A. Validation of the second version of a quantitative food-frequency questionnaire for use in Western Mali. Public Health Nutrition 2002; 5: 769-81.

22 Verma M, Raghuvanshi RS. Dietary iodine intake and prevalence of iodine deficiency. Journal of Nutritional and Environmental Medicine 2001; 11: 175-80.

23 Pandav CS, Arora NK, Krishnan A, Sankar R, Pandav S, Karmarkar MG. Validation of spot-testing kits to determine iodine content in salt. Bulletin of the World Health Organization 2000; 78: 975-80.

24 Eltom A, Eltom M, Elnagar B, Elgabir M, Gebre-Medhin M. Changes in iodine metabolism during late pregnancy and lactation: a longitudinal study among Sudanese women. European Journal of Clinical Nutrition 2000; 54: 429-33.

25 Glinoer D. Feto-maternal repercussions of iodine deficiency during pregnancy. An update. Annales d'Endocrinologie 2003; 64: 37-44 
26 Dunn JT, Delange F. Damaged reproduction: the most important consequence of iodine deficiency. Journal of Clinical Endocrinology and Metabolism 2001; 86: 2360-3.

27 Brander L, Als C, Buess H, Haldimann F, Harder M, Hanggi $\mathrm{W}$, et al. Urinary iodine concentration during pregnancy in an area of unstable dietary iodine intake in Switzerland. Journal of Endocrinological Investigation 2003; 26: 389-96.

28 Dorea JG. Iodine nutrition and breast feeding. Journal of Trace Elements in Medicine and Biology 2002; 16: 202-20.

29 Adesunkanmi AR, Makinde ON. Goitre prevalence in pregnant women attending antenatal clinic in a teaching hospital. Journal of Obstetrics and Gynaecology 2003; 32: 156-9.

30 Rotondi M, Amato G, Biondi B, Mazziotti G, Del Buono A, Rotonda Nicchio $\mathrm{M}$, et al. Parity as a thyroid size-determining factor in areas with moderate iodine deficiency. Journal of Clinical Endocrinology and Metabolism 2000; 85: 4534-7.

31 Knudsen N, Bülow I, Jørgensen T, Laurberg P, Ovesen L, Perrild $\mathrm{H}$. Goitre prevalence and thyroid abnormalities at ultrasonography: a comparative epidemiological study in two regions with slightly different iodine status. Clinical Endocrinology 2000; 53: 479-85.

32 Knudsen N, Bülow I, Laurberg P, Ovesen L, Perrild H, Jørgensen T. Parity is associated with increased thyroid volume solely among smokers in an area with moderate to mild iodine deficiency. European Journal of Endocrinology 2002; 146: 39-43.

33 Smyth PP, Hetherton AM, Smith DF, Radcliff M, O'Herlihy C. Maternal iodine status and thyroid volume during pregnancy: correlation with neonatal iodine intake. Journal of Clinical Endocrinology and Metabolism 1997; 82: 2840-3.

34 Rasmussen NG, Hornnes PJ, Hegedus L. Ultrasonographically determined thyroid size in pregnancy and post partum: the goitrogenic effect of pregnancy. American Journal of Obstetrics and Gynecology 1989; 160: 1216-20.

35 Glinoer D, Lemone M, Bourdouc P, De Nayer P, Delange F, Kinthaert J, et al. Partial reversibility during late postpartum of thyroid abnormalities associated with pregnancy. Journal of Clinical Endocrinology and Metabolism 1992; 74: 453-7.

36 Glinoer D. Pregnancy and iodine. Thyroid 2001; 11: 471-81.

37 Gaitan JE, Mayoral LG, Gaitan E. Defective thyroidal iodine concentration in protein-calorie malnutrition. Journal of Clinical Endocrinology and Metabolism 1983; 57: 327-33.

38 Tonglet R, Bourdoux P, Dramaix M, Hennart P, Ermans AM. Interobserver variation in the assessment of thyroid enlargement: a pitfall in surveys of the prevalence of endemic goitre. Food and Nutrition Bulletin 1994; 15: $64-70$.

39 Altman DG. Practical Statistics for Medical Research. London: Chapman \& Hall, 1997. 